\title{
TINJAUAN KONSTRIBUSI LEMBARAN CARBON FIBER TERHADAP KEKUATAN GESER PADA BALOK LANGSING
}

\author{
Edo Barlian \\ barlianedo11@gmail.com \\ Staf Pengajar Fakultas Teknik Universitas Negeri Medan \\ Jurusan Teknik Bangunan
}

\begin{abstract}
Abstrak
Dalam penelitian ini dimaksudkan untuk mengetahui perbandingan geser pada balok bertulang dengan jumlah tulangan geser kecil dari persyaratan minimal dengan balok beton bertulang yang diberi perkuatan lembaran carbon fiber secara analisa. Jumlah tulangan geser minimal dilakukan agar balok lemah terhadap geser. Pemakaian carbon fiber pada suatu konstruksi biasa nya disebabkan oleh terjadi kesalahan perencanaan, adanya kerusakan-kerusakan dari bagian struktur sehingga dikhawatirkan tidak berfungsi sesuai dengan yang diharapkan dan adanya perubahan fungsi pada system struktur dan adanya penambahan beban yang melebihi beban rencana. Analisa perhitungan dilakukan berdasarkan SNI 03-2847-2002 dan metode ACI 440. Dari hasil perhitungan menunjukkan bahwa lembaran carbon fiber bersama-sama dengan kuat geser nominal sumbangan dari beton dapat memberikan konstribusi geser pada balok beton.
\end{abstract}

\section{Kata Kunci: Geser, Carbon, Balok, Analisis, Kapasitas}

\begin{abstract}
In this study intended to determine the ratio of shear in beams reinforced with a small amount of shear reinforcement of minimum requirements with reinforced concrete beams were given a sheet of carbon fiber reinforcement in the analysis. The number of minimum shear reinforcement is done so that the beam is weak against shear. The use of carbon fiber on a regular construction were due to errors of planning, the existence of the damage from the structure so that it is feared not function as expected and the change in the function of the system structure and the addition of loads that exceed the design load. Analysis calculations are based on SNI 03-2847-2002 and methods of ACI 440. From the result shows that the sheet of carbon fiber together with the nominal shear strength of concrete donations may contribute sliding on concrete beams.
\end{abstract}

Keywords: Shear, Carbon, Beam, Analysis, Capacity

\section{PENDAHULUAN}

\subsection{Latar Belakang Masalah}

Elemen struktur bangunan yang dikenal dan banyak dimanfaatkan sampai saat ini salah satunya adalag beton. Beton banyak mengalami perkembangan, baik dalam pembuatan campuran maupun dalam pelaksanaan konstruksinya.

Pada balok beton bertulang sebagai elemen struktur harus diberi penulangan yang berupa penulangan lentur (memanjang) dan penulangan geser. Penulangan lentur berfungsi sebagai penahan beban momen lentur yang terjadi pada balok. Penulangan geser (sengkang) berfungsi sebagai penahan beban geser (gaya lintang) yang terjadi pada balok. Ada beberapa macam tulangan sengkang pada balok, yaitu pelaksanaan perkuatan berdasar peraturan beton SNI 2847-2002, yang diharapkan dapat memberikan solusi permasalahan sehingga sengkang vertikal, sengkang spiral, dan sengkang miring.

Karena penggunaan beton pada saat ini semakin meningkat, maka perlu dikembangkan penggunaan bahan-bahan alternatif yang diperkirakan dapat memperbaiki atau meningkatkan mutu beton bertulang. Salah satu usaha yang dilakukan yaitu mengupayakan agar beton mempunyai kuat lentur dan geser tinggi. Seperti diketahui bahwa struktur beton yang tidak direncanakan dengan adanya tegangan geser, akan mengalami masalah yaitu retak pada struktur tersebut akibat beban yang mengenainya, dimana struktur tidak mampu menahannya.

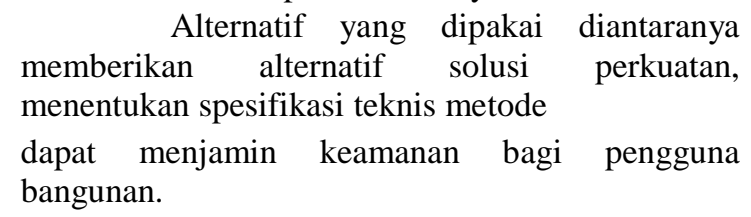

Tinjauan Konstribusi Lembaran Carbon Fiber Terhadap -46

Kekuatan Geser Pada Balok Langsing

Edo Barlian 


\subsection{Perumusan Masalah}

Dalam perencanaan struktur beton bertulang, diperlukan suatu keamanan struktur terhadap keruntuhan yang mungkin terjadi selama umur bangunan. Keruntuhan yang cukup fatal dalam konstruksi balok beton bertulang adalah keruntuhan lentur tarik diagonal dan geser tarik. Beban yang melebihi kapasitas penampang balok beton bertulang akan mengakibatkan retakan-retakan diagonal disepanjang balok beton. Jika balok tersebut tidak memiliki jumlah tulangan transversal dan tulangan longitudinal yang cukup serta didetail dengan benar, retakan tersebut dapat terjadi lebih awal dan pada akhirnya akan berakibat terjadi keruntuhan yang tiba-tiba. Sehingga yang sangat perlu untuk diperhatikan adalah kegagalan geser pada bagian struktur beton, karena kegagalan geser merupakan keruntuhan getas yang berakibat fatal.

Dalam tulisan ini akan mengkaji sejauh mana besar peningkatkan kekuatan geser pada balok langsing terhadap penggunaan woven carbon fiber sebagai bahan alternatif untuk menambah kekuatan geser pada balok.

\subsection{Tujuan}

Tujuan penelitan penggunaan woven carbon fiber sebagai bahan untuk menambah perkuatan pada balok adalah: untuk mengetahui seberapa besar penambahan kekuatan geser terhadap balok

\subsection{BATASAN MASALAH}

Berdasarkan identifikasi masalah, maka perlu dilakukan penelitian untuk meninjau kontribusi lembaran woven carbon fiber terhadap geser pada balok langsing. Ruang lingkup penelitian ini adalah:

1. Mutu beton yang direncanakan adalah beton $\mathrm{K}-\quad 250$;

2. Benda uji pada balokbeton bertulang dengan tulangan tarik, tulangan tekan dan tulangan geser minimum;

3. Lembaran woven carbon fiber dipasang vertical dengan perkuatan perekat

4. Analisa perhitungan dilakukan berdasarkan SNI 03-2847-2002 dan metode ACI 440.

\section{I.5 TAHAPAN PELAKSANAAN PENGUJIAN}

Tahapan pelaksanaan pengujian pada penelitian ini adalah:

1. Tahap Persiapan; pengumpulan bahan literatus dan penyediaan material

2. Tahap pengujian material; semen, agregat halus, agregat kasar, baja tulangan dan mix design

3. Tahap pembuatan benda uji; pembuatan cetakan beton, merakit tulangan, pengecoran, perawatan benda uji

4. Tahap pengujian benda uji

5. Analisa data

\section{TINJAUAN PUSTAKA \\ 2.1 DESKRIPSI BETON}

Beton merupakan campuran dari pasir, kerikil, semen dan air sehingga membentuk suatu massa. Untuk menghasilkan beton dengan karakteristik tertentu dapat ditambahkan bahan aditif pada campuran. Jika beton yang memiliki kuat tekan yang tinggidi kombinasikan dengan baja yang berfungsi sebagai kuat tarik maka disebut beton bertulang.

Dalam SNI 03-2847-2002, beton merupakan campuran antara semen portland atau semen hidraulik yang lain, agregat halus, agregat kasar dan air, dengan atau tanpa bahan tambahan yang membentuk masa padat. Beton bertulang adalah beton yang ditulangi dengan luas dan jumlah tulangan yang tidak kurang dari nilai minimum, yang disyaratkan dengan atau tanpa prategang, dan direncanakan berdasarkan asumsi bahwa kedua material bekerja bersama-sama dalam menahan gaya yang bekerja.

Dalam Nawy (1990), Nilai kuat tekan beton dengan kuat tariknya tidak berbanding lurus. Setiap usaha perbaikan mutu kekuatan tekan hanya disertai oleh peningkatan yang kecil dari kuat tariknya.

Kecilnya kuat tarik dari beton ini merupakan salah satu kelemahan beton biasa. Untuk mengatasinya beton dikombinasikan dengan tulangan beton dimana baja biasa digunakan sebagai tulangannya, dengan alasan karena koefsien baja hamper sama 
dengan kofisien beton (Tri Mulyono, 2004).

\subsubsection{Semen Portland}

Semen Portland dibuat dari serbuk halus mineral kristalin yang komposisi utamanya adalah kalsium dan alumunium silikat. Penambahan air mineral ini menghasilkan suatu pasta yang jika mongering akan mempunyai kekuatan seperti batu (Nawy, 1985).

Kekuatan semen merupakan hasil dari proses hidrasi. Proses kimiawi ini berupa rekritalisasi delam bentuk interlockingcrystals sehingga membentuk gel semen yang akan mempunyai kekuatan tekan tinggi apabila mengeras (Nawy, 1985).

Secara umum perencanaan campuran beton yang akan digunakan dalam pelaksanaan konstruksi beton harus memenuhi persyaratan seperti (1) kekuatan desak yang dicapai dalam umur 28 hati atau umur yang ditentukan; (2) tingkat keawetan beton, sama pentingnya dengan kekuatan beton, dengan tingkat kekuatan hancur yang besar akan semakin awet betonnya; (3) kemudahan pekerjaan, dimana secara umum campran beton harus memberikan workability yang cukup untuk pengaduka, pencetakan, dan pemadatan tanpa pengurangan homegenetis.

\subsubsection{Air}

Air diperlukan pada pembuatan beton agar terjadi reaksi kimiawi dengan semen untuk membasahi agregat dan untuk melumas campuran agar mudah pekerjaannya. Pada umumnya air minum dapat dipakai untuk campuran beton. Air yang mengandung senyawa-senyawa yang berbahaya, yang tercemar garam, minyak, gula, atau bahanbahan kimia lainnya, bila dipakai untuk campuran beton akan sangat menurunkan kekuatannya dan dapat juga merubah sifatsifat semen (Nawy, 1990).

\subsubsection{Agregat}

Agregat yang digunakan dalam beton menempati sekitar $3 / 4$ bagian darivolume beton, baik agregat halus maupun agregat kasar. Agregat harus kuat, tahan lama dan bersih. Jika terdapat debu atau partikel lain akan mengurangi ikatan antara pasta semen dengan agregat. Kekuatan agregat memberikan pengaruh penting pada kekuatan beton dan sifat-sifat agregat sangat mempengaruhi daya tahan beton. (McCormac, 2001)

Agregat halus dan agregat kasar yang digunakan sebagai bahan pengisi beton harus memenuhi persyaratan-persyaratan.

\subsubsection{Baja Tulangan}

Dalam Nawy, 1985, baja tulangan untuk beton terdiri dari batang, kawat dan jarring kawat baja las yang seluruhnya dirakit sesuai dengan standar ASTM. Sifat-sifat terpenting baja tulangan adalah:

a. Modulus young, $\epsilon \mathrm{S}$

b. Kekuatan leleh, $f_{V}$

c. Kekuatan batas, $f_{u}$

d. Mutu baja yang ditentukan

e. Ukuran atau diameter batang atau kawat

\subsection{LENTUR PADA BALOK}

Dalam Nawy (1990), apabila bebannya bertambah, maka pada balok terjadi deformasi dan regangan tambahan yang mengakibatkan timbulnya (bertambahnya retak) lentur disepanjang bentang balok. Bila bebannya semakin bertambah, pada akhirnya dapat terjadi keruntuhan elemen struktur, yaitu pada saat beban luarnya mencapai

kapasitas elemen. Taraf pembebanan demikian disebut keadaan limit dari keruntuhan pada lentur.

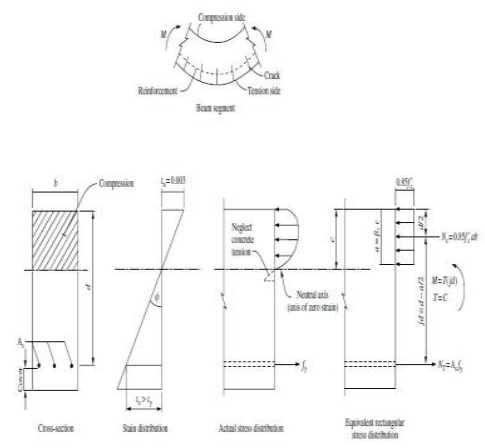

Gambar 2.1. Distribisi tegangan dan regangan pada balok 


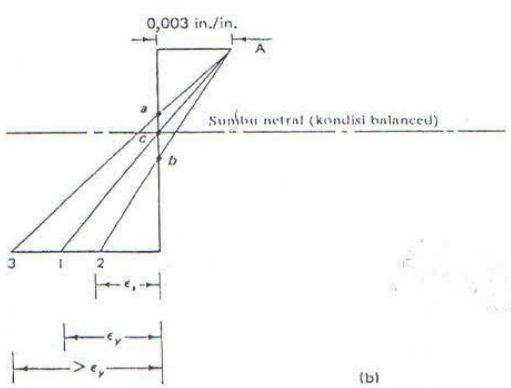

Gambar 2.2 Distribusi regangan penampang balok: a) Diagram tegangan tulangan baja yang diidealisasikan; b) Distribusi regangan untuk berbagai ragam keruntuhan lentur.

$$
\text { Keterangan mengenai diagram }
$$
distribusi regangan dan tegangan serta keseimbangan gaya-gaya pada penampang beton dan dilihat kerja sama antara beton dan baja tulangan dalam melawan lenturan sepertiyang tertera pada Gambar 2.3.

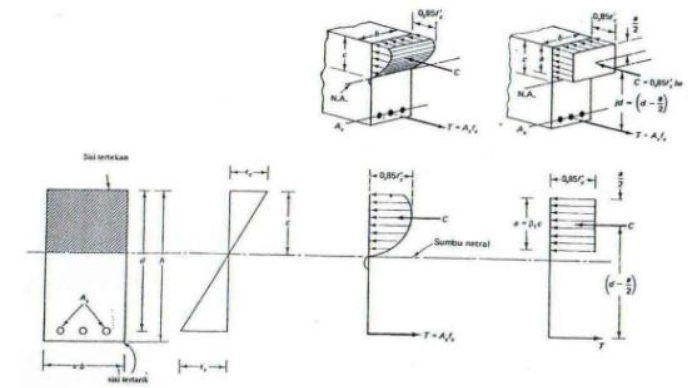

Gambar 2.3 Distribusi tegangan dan regangan pada penampangan balok, penampang melintang balok, balok regangan ekuivalen yang diasumsikan.

\subsection{GESER PADA BALOK}

Analisa dan desain pada penampang beton bertulang terhadap geser yang diakibatkan oleh bekerjanya beban luar merupakan hal yang sangat penting dalam struktur beton, karena kekuatan tarik beton jauh lebih kecil dibandingkan dengan kekuatan tekannya. Perilaku balok beton yang runtuh akibat geser sangat berbeda dengan runtuh yang diakibatkan lentur, dimana bentuk retak diagonalnya lebih besar dibanding retak lentur. Keruntuhan akibat geser menyebabkan balok langsung hancur tanpa adanya tanda-tanda dan peringatan terlebih dahulu.

Gambar berikut memperlihatkan jenis-jenis retak pada balokyang tertera pada Gambar 2.4.

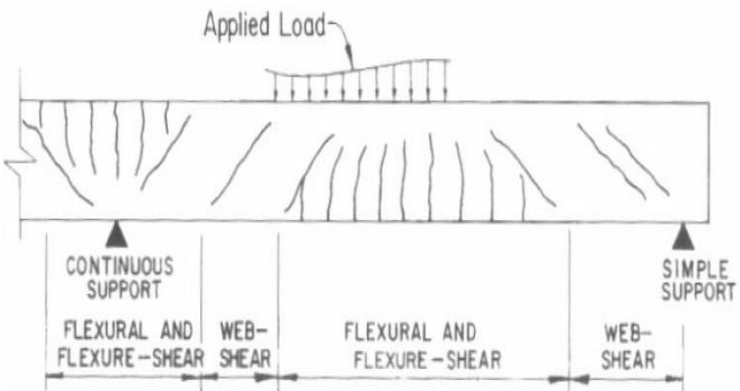

Gambar 2.4 Jenis-jenis retak

\subsubsection{Tegangan geser}

Setiap balok yang yang bersifat homogen, alastik dan belum retak jika diberikan beban pasti akan mengalami gaya geser pada setiap penampangnya, dan tegangan geser yang terjadi adalah:

$$
v=\frac{V . S}{b . I}
$$

Dalam SNI 03-2847-2002, menjelaskan bahwa: perencanaan penampang geser harus didasarkan pada:

$$
\emptyset V u \geq V n
$$

Kuat geser nominal dapat dihitung dari:

$$
V n=V c+V s
$$

Analog rangka merupakan konsep lama dari struktur beton bertulang. Konsep ini manyatakan bahwa dalam menahan geser yang bekerja pada balok terbentuk rangka badan ekovalen yang terdiri dari sengkang-sengkang yang bekerja sebagai elemen tarik dan strut beton yang parallel dengan retak diagonal bekerja sebagai elemen tekan. Strut tekan beton ini membentuk sudut $45^{\circ}$ terhadap sumbu longitudinal balok. Tahanan geser $V n$ diasumsikan terdiri atas tahanan geser tulangan sengkang $V s$ dan tahanan geser beton $V c$.

\subsubsection{Kuat geser nominal yang disumbangkan oleh beton}

Kuat geser $V c$ harus dihitung berdasarkan komponen struktur yangdibebani oleh geser dan lentur, dapat dihitung dari:

Tinjauan Konstribusi Lembaran Carbon Fiber Terhadap -49 Kekuatan Geser Pada Balok Langsing Edo Barlian 


$$
V c=\left(\frac{\sqrt{f r c}}{6}\right) b w \cdot d
$$

Dan jika kuat geser dihitung berdasarkan komponen struktur yang dibebani tekan aksial, dapat dihitung dari:

$$
V c=\left(1+\frac{N u}{14 \cdot A g}\right)\left(\frac{\sqrt{f \prime c}}{6}\right) b w \cdot d
$$

Jika komponen struktur yang mengalami gaya tarik aksial yang besar, dapat dihitung dari:

$$
V c=\left(1+\frac{0,3 N u}{A g}\right) \frac{\sqrt{f r c}}{6} b w \cdot d
$$

\subsubsection{Kuat geser nominal yang disumbangkan oleh tulangan geser}

Kuat geser $V s$ dihitung berdasarkan posisi tulangan geser yang digunakan, bila digunakan tulangan geser yang tegak lurus terhadap sumbu aksial komponen struktur, maka kuat geser nominal yang disumbangkan oleh tulangan geser dihitung berdasarkan:

$$
V s=\frac{A v \cdot f y \cdot d}{s}
$$

\subsection{FIBER REINFORCED POL YMER}

Fiber Reinforced Polymer (FRP) merupakan sejenis pelat baja tipis yang didalamnya terdapat serat-serat carbon dan fiber.Tiga prinsip penggunan FRP dalam perkuatan struktur adalah: (1) Meningkatkan kapasitas momen lentur pada balok atau plat dengan menambahkan FRP pada bagian tarik. (2) Meningkatkan kapasitas geser pada balok dengan menambahkan FRP di bagian sisi pada daerah geser, dan (3) Meningkatkan kapasitas beban axial dan geser pada kolom dengan menambahkan FRP di sekeliling kolom.

Bentuk FRP yang sering dipakai pada perkuatan struktur adalah plate/composite dan fabri/ Wrap. Bentuk Plate lebih efektif dan efisien untuk perkuatan lentur baik pada balok maupun plat serta pada dinding ; sedang bentuk wrap lebih efektif dan efisien untuk perkuatan geser pada balok serta untuk meningkatkan kapasitas beban axial dan geser pada kolom (Hartono, 2002).

\subsubsection{Standard Pedoman Perencanaan}

Pedoman perencanaan untuk FRP dapat mengacu pada standard ACI yaitu ACI 440-Guide for the Design and Construction of
Externally Bonded FRP System for Strengthening Concrete Structures and Technical Report yang dikeluarkan oleh Concrete Society Committee Inggris yaitu Technical Report No. 55-Design Guidance for Strengthening Concrete Structure Using Fibre Composite Material.

\subsubsection{Aplikasi FRP}

FRP (fiber reinforced polymer) digunakan pada konstruksi yang telah ada. Pemakaian FRP pada suatu konstruksi biasa nya disebabkan oleh beberapa hal seperti: terjadi kesalahan perencanaan, adanya kerusakan-kerusakan dari bagian struktur sehingga dikhawatirkan tidak berfungsi sesuai dengan yang diharapkan dan adanya perubahan fungsi pada system struktur dan adanya penambahan beban yang melebihi beban rencana.

\subsection{GESER DAN TARIK DIAGONAL}

Meskipun belum seorangpun yang mampu menentukan dengan tepat daya tahan beton terhadap tegangan geser murni, hal ini tidak terlalu penting karena tegangan geser murni mungkin tidak pernah terjadi dalam struktur beton. Lebih dari itu, sesuai dengan mekanika teknik, jika geser murni dihasilkan dalam suatu batang, tegangan tarik utama dengan besar yang sama akan dihasilkan pada bidang yang lain. Karena kekuatan tarik beton lebih kecil dari kekuatan geser, maka beton akan runtuh dalam tarik sebelum kekuatan gesernya tercapai. Akan tetapi, pengujian kuat geser beton selama bertahun-tahun selalu menghasilkan nilai-nilai leleh yang terletak di antara 1/3 sampai 4/5 dari kuat tekan maksimumnya.

\subsubsection{Retak Geser dari Balok Beton Bertulang}

Retak miring karena geser dapat terjadi pada bagian web balok beton bertulang baik sebagai retak bebas atau sebagai perpanjangan dari retak lentur. Retak pertama dari kedua jenis retak ini adalah retak lenturgeser. Ini adalah jenis retak yang biasanya dijumpai dalam balok prategang maupun non prategang. Agar retak ini terjadi, momen harus lebih besar dari momen retak dan geser. Retak harus membentuk sudut sekitar $45^{\circ}$ dengan 
sumbu balok dan mungkin diawali pada puncak retak lentur. Retak lentur yang hamper vertical tidak berbahaya kecuali jika ada kombinasi kritis dari tegangan geser dan tegangan lentur yang terjadi pada puncak salah satu retak lentur. (Nawy, 1985).

\subsubsection{Analisa Kuat Geser Balok Tanpa Tulangan Geser}

Setelah retak berkembang, batang akan runtuh kecuali penampang beton yang retak dapat menahan gaya yang bekerja. Transfer dari geser di dalam unsur-unsur beton bertulang tanpa tulangan geser terjadi dengan suatu kombinasi dari antara beberapa mekanisme sebagai berikut:

1. Perlawanan geser dari penampang yang tak retak di atas bagian yang retak, $V_{C Z}$ (diperkirakan sekitar $20 \%$ s.d $40 \%)$.

2. Gaya ikat (interlocking) antara agregat (atau transfer geser antara permukaan) dalam arah tangensial sepanjang suatu retak, yang serupa dengan gaya gesek akibat saling ikat yang tidak teratur dari agregat sepanjang permukaan yang kasar dari beton pada masing-masing pihak yang retak (diperkirakan 30\% s.d 50\%).

3. Aksi pasak (dowel action) $V_{d}$, sebagai perlawanan dari penulangan longitudinal terhadap gaya transversal (diperkirakan $15 \%$ s.d $25 \%$ ).

4. Aksi pelengkung (arch action) pada balok yang relatif tinggi. (Nawy, 1985).

\subsubsection{Analisa Kuat Geser Balok Yang Bertulangan Geser Mekanisme Analogi Rangka (vakwerkanalogi)}

Analogi rangka merupakan konsep lama dari struktur beton bertulang. Konsep ini menyatakan bahwa balok beton bertulang dengan tulangan geser dikatakan berperilaku seperti rangka batang sejajar statis tertentu dengan sambungan sendi. Beton tekan lentur dianalogikan sebagai batang atas rangka batang, sedangkan tulangan tarik sebagai batang bawah. Web rangka batang tersusun dari sengkang sebagai batang tarik vertikal dan bagian beton antara retak tarik diagonal mendekati $45^{\circ}$ bekerja sebagai batang tekan diagonal. Tulangan geser yang digunakan berperilaku seperti batang web dari suatu rangka batang. (Nawy, 1985).

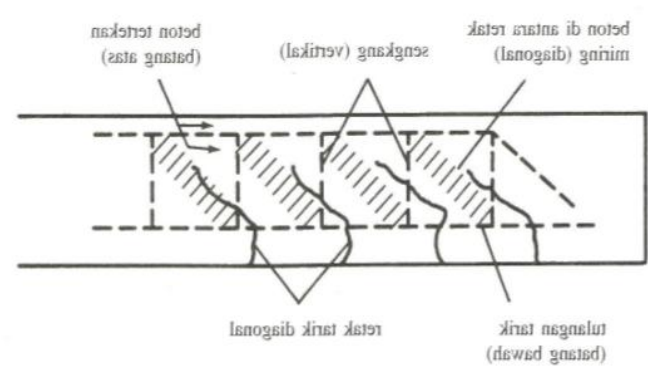

Gambar: Mekanisme analogi rangka batang

Meskipun analogi rangka batang telah digunakan bertahun-tahun untuk menjelaskan perilaku balok beton bertulang dengan tulangan web, tetapi tidak menjelaskan dengan tepat bagaimana gaya geser dipindahkan. Tentu saja penulangan geser akan meningkatkan kekuatan geser dari suatu unsur, akan tetapi penulangan sedemikian hanya akan menyumbangkan sedikit perlawanan geser sebelum terbentuknya retak miring.

Retak diagonal akan terjadi dalam balok dengan tulangan geser pada beban yang hampir sama jika retak tersebut terjadi dalam balok dengan ukuran yang sama tetapi tanpa tulangan geser. Adanya tulangan geser hanya dapat diketahui setelah retak mulai terbentuk. Pada saat itu, balok harus mempunyai tulangan geser yang cukup untuk menahan gaya geser yang tidak ditahan oleh beton.

\subsection{RAGAM KEGAGALAN BALOK}

Perbandingan antara bentang bersih dengan tinggi balok disebut kelangsingan balok merupakan penentu dalam keruntuhan balok. Pada dasarnya terjadi 3 (tiga) ragam keruntuhan, yaitu: keruntuhan lentur, keruntuhan tarik diagonal dan keruntuhan tekan akibat geser.

\subsubsection{Keruntuhan Lentur}

Pada daerah yang mengalami keruntuhan lentur, retak terjadi pada sepertiga tengah bentang dan tegak lurus arah tegangan utama. Retak tersebut diakibatkan oleh tegangan geser vyang sangat kecil dan tegangan lentur yang dominan yang besarnya hampir mendekati tegangan utama horizontal. 
Dalam keadaan runtuh lentur demikian, beberapa retak halus berarah vertical terjadi didaerah tengah bentangsekitar 50\% dari yang diakibatkan oleh beban runtuh lentur. Apabila beban bertambah terus, retak-retak ditengah bentang bertambah dan retak awal yang terjadi bertambah lebar dan semakin panjang menuju sumbu netral penampang. Hal ini bersamaan dengan semakin besarnya lendutan ditengah bentang. Jika balok tersebut under-reinforced, maka keruntuhan ini merupakan keruntuhan yang daktail (ductile) yang ditanda dulu dengan lelehnya tulangan tarik. Perilaku diktail ini memberikan peringatan terlebih dahulu kepada pemakai bangunan sebelum terjadi kehancuran total balok. Agar berperilaku daktail biasanya perbandingan antara bentang geser dengan tinggi penampang harus lebih besar dari 5,5 dalam hal beban terpusat dan melebihi 15 untuk beban terdistribusi (Nawy, 1998).

\subsubsection{Keruntuhan Tarik Diagonal}

Keruntuhan ini dapat terjadi apabila kekuatan balok dalam diagonal terik lebih kecil dari pada kekuatan lenturnya. Perbandingan antara bentang geser dengan tinggi penampang adalah menengah, yaitu a/d bervariasi antara 2,5 dan 5,5 untuk beban terpusat. Balok demikian disebut balok kelangsingan menengah. Retak-retak mulai terjadi ditengah bentang, berarah vertical yang berupa retak halus dan diakibatkan oleh lentur. Hal ini diikuti dengan rusaknya lekatan antara baja tulangna dengan beton disekitarnya pada perletakan. Maka tanpa adanya peringatan sebelum runtuh, dua atau tiga retak diagonal terjadi pada jarak sekitar $1,5 \mathrm{~d}$ sampai $2 \mathrm{~d}$ dari muka perletakan. Untuk mencapai kestabilan, satu retak diagonal ini melebar kedalam retak tarik diagonal utama (Nawy, 1998).

\subsubsection{Keruntuhan Tekan Geser}

Balok-balok yang mengalami
keruntuhan demikian perbandingan antara bentang geser dengan tinggi penampang a/d sebesar 1 sampai 2,5 untuk beban terpusat dan kurang dari 5,0 untuk beban terdistribusi. Keruntuhan ini dimulai dengan timbulnya retak lentur vertical ditengah bentang dan tidak terus menjalar karena terjadi kehilangan lekatan antara tulangan membujur (longitudinal) dengan beton disekitarnya pada daerah perletakan. Setelah itu diikuti dengan retak miring yang lebih curam daripada retak diagonal tarik, secara tiba-tiba dan menjalar terus menuju sumbu netral. Kecepatan menjalar ini semakin berkurang sebagai akibat dari hancurnya beton pada tepi tertekan dan terjadi retribusi tegangan pada daerah atas. Pada saat bertemunya terak miring ini dengan tepi beton yang tertekan, terjadilah keruntuhan secara tiba-tiba. Ragam keruntuhan ini dapat dipandang kurang getas dibandingkan dengan ragam keruntuhan tarik diagonal karena adanya retribusi regangan.

\subsection{Kontribusi Lembaran FRP Dalam Memikul Lentur dan Geser}

\subsubsection{Konstribusi Lembaran FRP Terhadap Lentur \\ Perhitungan perkuatan lentur dengan}

FRP mengacu pada ACI committee 440. Analisa perkuatan FRP terhadap lentur yang tertera pada Gambar berikut:

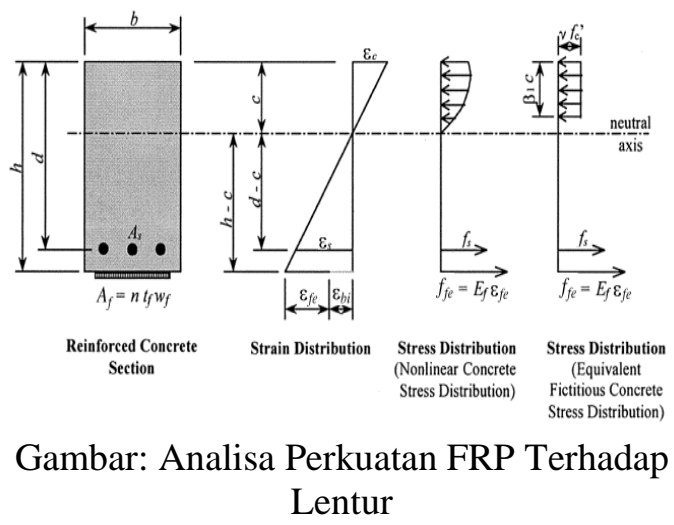

\subsubsection{Kontrubusi Lembaran FRP Terhadap Geser \\ Dalam mendesain kekuatan lentur} diperlukan faktor reduksi terhadap momen yang terjadi.Berdasarkan analogi rangka, kontribusi lembaran FRP dalam memikul gaya geser yang bekerja dapat diperhitungkan dengan menambahkan suku Vf pada persamaan (ACI Committee 440) sehingga:

$$
\phi V n=\phi(V c+V s+\psi V f)
$$

\section{BAHAN DAN METODE}

Tinjauan Konstribusi Lembaran Carbon Fiber Terhadap -52 Kekuatan Geser Pada Balok Langsing Edo Barlian 
Selanjutnya benda uji kubus direndam air dalam kolam perawatan yang telah disiapkan sampai pada masa pengujian. Untuk balok ujiperawatan dilakukan dengan menutupi dengan goni basah dan disiram air setiap hari.

\subsection{Prosedur Pengambilan data}

\subsubsection{Pengujian silinder beton}

Ambil benda uji berupa silinder beton yang akan ditentukan kekutan tekanan dari bak perendam, kemudian bersihkan dari kotoran yang menempel dengan kain pelembab. Tentukan berat dan ukuran benda uji.Letakkan benda uji pada mesin kompres berkapasitas 200 ton secara sentries. sesuai dengan tempat yang tepat pada mesin tes kuat tekan beton.Jalankan benda uji atau mesin tekan dengan penambahan beban konstan berdasar 2 sampai $4 \mathrm{~kg} / \mathrm{cm} 2$ per detik.Lakukan pembebanan sampai benda uji menjadi hancur dan catatlah beban maksimum yang terjadi selama pemeriksaan benda uji.Pengujian kuat tekan beton ini dilakukan pada saat beton berumur 28 hari lalu diambil rata-rata.

\subsubsection{Pengujian balok beton bertulang}

Pengujian balok bertulang dilakukan setelah balok tersebut berumur 28 hari.Alat yang digunakan adalah Jack Hydraulik yang berkapasitas 25 ton. Balok uji ditempatkan pada perletakan dan diberi beban terpusat $\mathrm{P}$ yang merupakan titik pembebanan membagi balok dengan jarak yang sama masing-masing $100 \mathrm{~cm}$. Untuk mengukur lenturan balok ditempatkan 3 buah dial indicator, yaitu sisi kiri atas (Y1), sisi kanan atas (Y2) dan bawah (Y3) dengan jarak msing-masing $60 \mathrm{~cm}$. Sebelum dibebani, jarum-jarum penunjuk dial indicator ini harus pada posisi nol. Bebap $\mathrm{P}$ pada tahap awal diberi sebesar 1 ton dan selanjutnya ditambah secara bertahap sebesar 0.5 ton. Besarnya beban $\mathrm{P}$ yang diberikan dapat dibaca pada manometer jack. Untuk setiap tahap pembebanan dibaca dan dicatat lenturan yang terjadi pada ketiga dial indicator.

\subsection{Perhitungan geser rencana 3.4.1 Perhitungan geser rencana pada balok uji I}

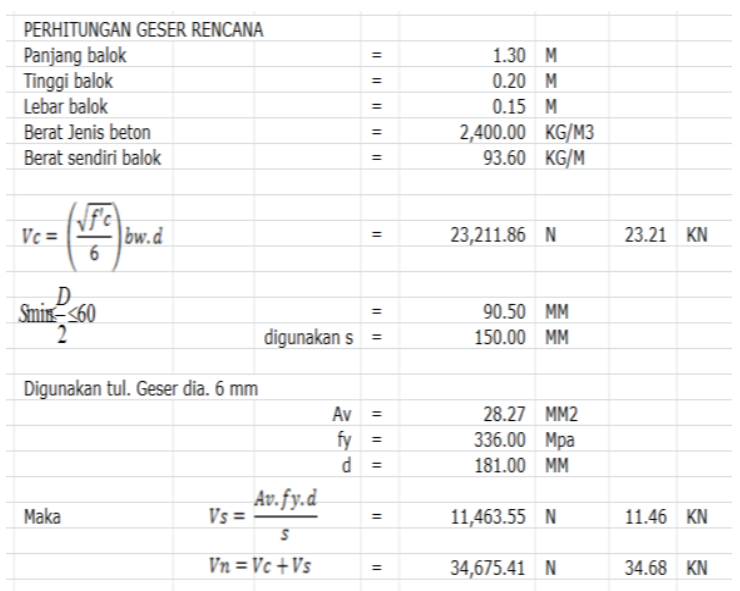

\subsubsection{Perhitungan geser rencana pada balok uji II}

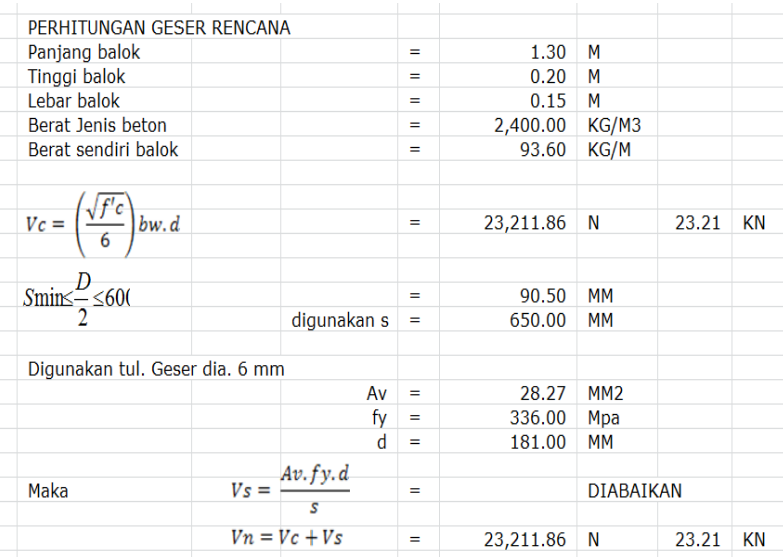

\subsubsection{Perhitungan geser rencana pada balok uji III}




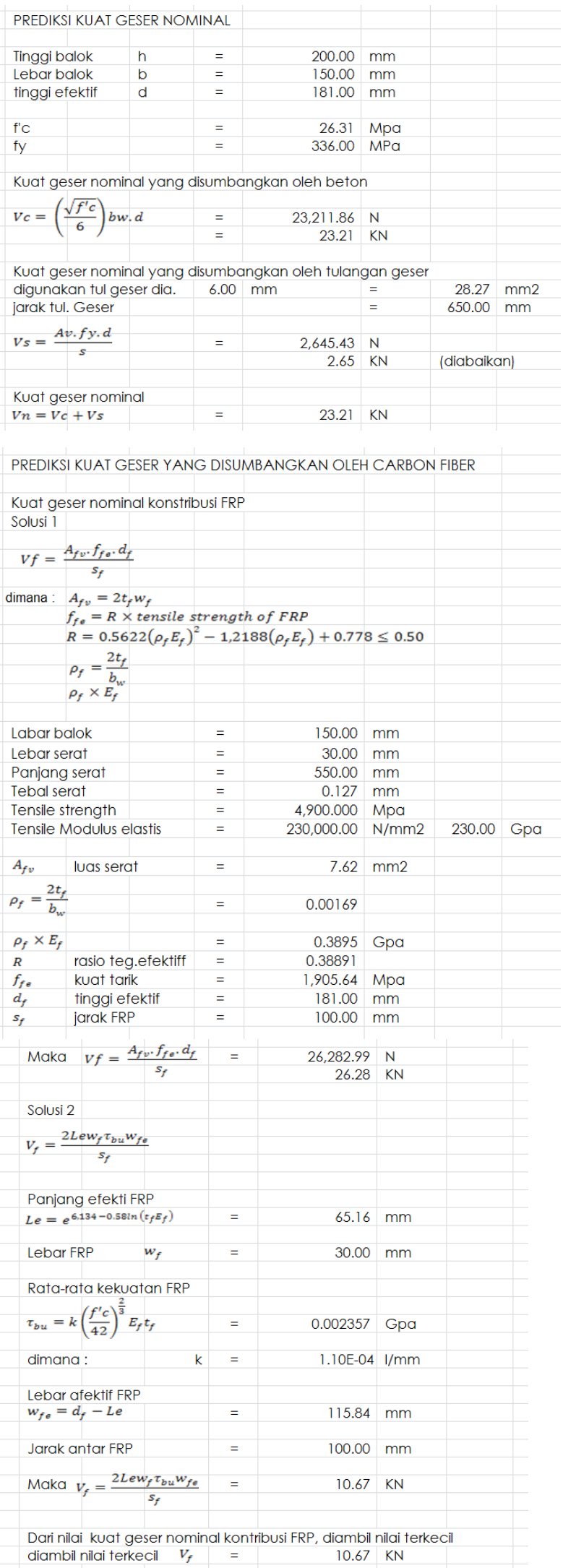

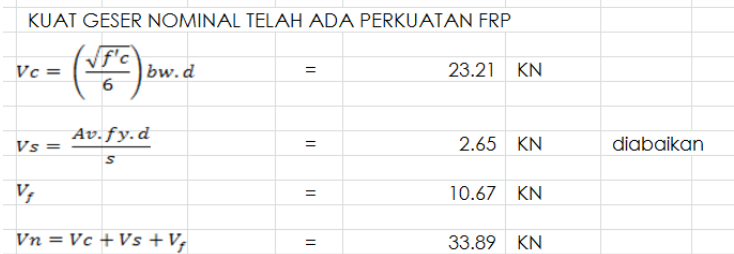

Untuk nilai $\Phi=\quad 0.85$ untuk geser dari sumbangan beton dan baja $\Phi=\quad 0.70$ untuk geser dari sumbangan carbon fiber

$\Phi V n=\Phi(V c+V s)+\Phi V_{f}=27.20 \mathrm{KN}$

\subsubsection{Perhitungan geser rencana pada balok uji IV}

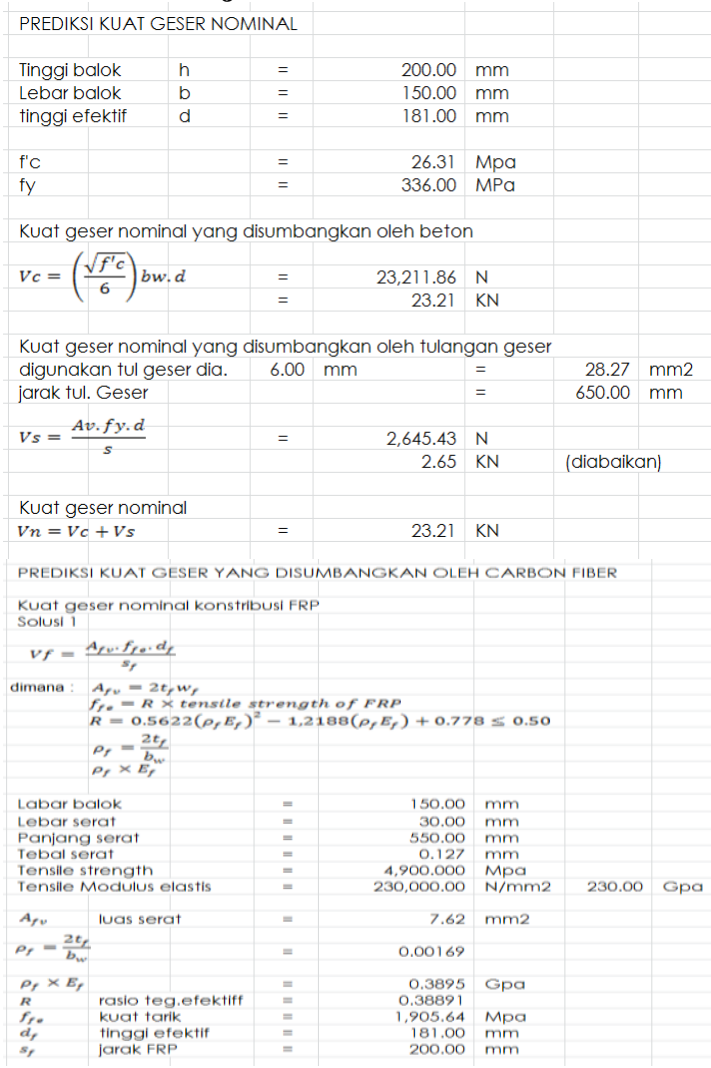




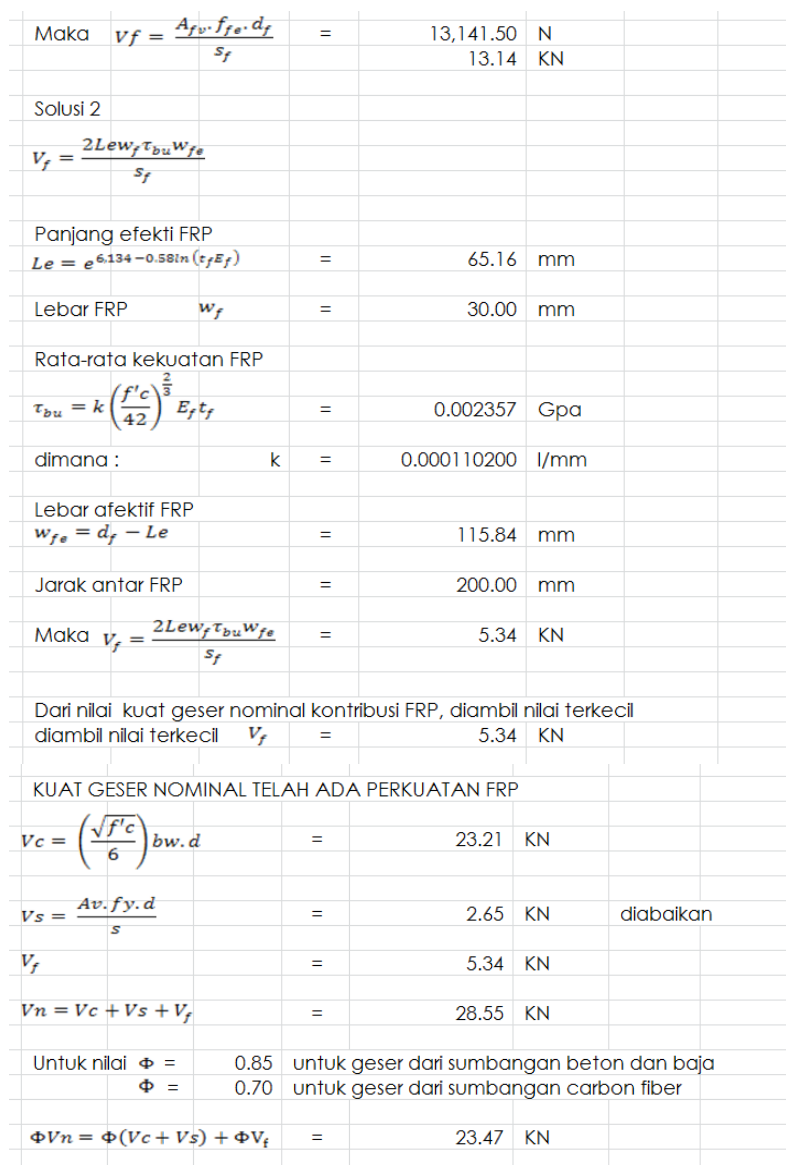

\section{HASIL DAN PEMBAHASAN}

Berdasarkan hasil perhitungan kuat geser nominal sumbangan beton, tulangan geser dan lembaran FRP dapat dilihat terjadi peningkatan kuat geser dengan perkuatan FRP, hasil perhitungan dapat dilohat pada tabel 4.1

Tabel 4.1 hasil perhitungan kuat geser nominal

\begin{tabular}{lcc|c|c|r}
\hline KUAT GESER & SAT & BU I & BU II & BU III & BU IV \\
\hline Disumbangkan oleh beton & $\mathrm{kn}$ & 23.21 & 23.21 & 23.21 & 23.21 \\
\hline Disumbangkan oleh tulangan geser & $\mathrm{kn}$ & 11.46 & - & - & - \\
\hline Kuat geser nominal beton dan tulangan & $\mathrm{kn}$ & 34.68 & 23.21 & 23.21 & 23.21 \\
\hline Kontribusi FRP solusi 1 & $\mathrm{kn}$ & - & - & 26.28 & 13.14 \\
\hline Kontribusi FRP solusi 2 & $\mathrm{kn}$ & - & - & 10.67 & 5.34 \\
\hline Kontribusi nominal FRP & $\mathrm{kn}$ & - & - & 10.67 & 5.34 \\
\hline Kuat geser nominal & $\mathrm{kn}$ & 34.68 & 23.21 & 27.20 & 23.47 \\
\hline
\end{tabular}

Pada balok uji I kuat geser nominal yang terjadi sebesar $34.68 \mathrm{KN}$, pada balok uji II kuat geser nominal sebesar $23.21 \mathrm{KN}$ dengan mengabaikan kuat geser yang disumbangkan oleh tulangan geser. Untuk balok uji III dengan perkuatan lembaran FRP kuat geser nominal yang terjadi sebesar 27.20 KN dan balok uji IV sebesar $23.47 \mathrm{KN}$. Ini menunjukkan bahwa lembaran FRP dapat memberikan kontribusi geser pada balok, dimana terjadi peningkatan kuat geser pada balok uji III dan balok uji IV terhadap balok uji II.

\section{KESIMPULAN DAN SARAN 5.1 Kesimpulan}

Berdasarkan hasil pengujian dan analisa teoritis yang telah dilakukan dapat ditarik kesimpulan sebagai berikut:

1. Pada balok uji II, balok uji III dan balok uji IV kuat geser yang disumbangkan oleh tulangan geser diabaikan karena nilai tegangan geser kecil yang disebabkan jarak antara tulangan $650 \mathrm{~mm}$ dan tulangan geser berfungsi sebagai pengikat tulangan tekan dan tulangan tarik.

2. Lembaran FRP dapat memberikan konstribusi geser pada balok.

\subsection{Saran}

Dengan memperhatikan kesimpulan dan kesulitan-kesulitan yang diperoleh selama penelitian, maka diberikan saran sebagai berikut:

1. Untuk menghasilkan hasil yang lebih akurat, perlu kiranya penambahan balok uji sebagai syarat statistic untuk mengambil kesimpulan

2. Untuk mendapatkan nilai besarnya kuat geser yang lebih akurat dan parameterparameter yang lainnya sebaiknya dilakukan dengan menggunakan peralatan pengujian yang lebih baik, akurat dan lengkap

3. Perlu dilakukan uji eksperimen sejenis dengan bentang dan dimensi benda uji yang lebih besar dan perletakan FRP bervariasi.

\section{DAFTAR PUSTAKA}

ACI Committee 318, (2002): "Building Code Requirements for Structural Concrete (318-02) and Commentary (318R-

02)," American Concrete Institute, Farmington Hills,Michigan, 443p.

ACI Committee 440. (2003). "Guide for the Design and Construction of Concrete Reinforced with FRP Bars," ACI 440.1R-03, American Concrete Institute, FarmingtonHills, Mich., 41p.

Tinjauan Konstribusi Lembaran Carbon Fiber Terhadap -56 Kekuatan Geser Pada Balok Langsing Edo Barlian 
Chajes $\mathrm{M}$, januska $\mathrm{T}$, Mertz $\mathrm{D}$, Thomson $\mathrm{T}$ and Finch W., " shear strengthening of reinforced concrete beams using externally applied composite fabrics." ACI structural journal, Vol.92. No.3, pp.295-303

Dipohusodo, istimawan., "Struktur beton bertulang berdasarkan SK-SNI T-151991-03, Edisi Pertama, Penerbit: Erlangga, Jakarta, 1994

Nawy, Edward G., "Beton bertulang, suatu pendekatan dasar." Cetakan kedua, Penerbit: PT. Refika Aditama, Bandung, 1998

Ignatius Christiawan, Andreas Triwiyono, Hary Christady. " EVALUASI KINERJA DAN PERKUATAN STRUKTUR GEDUNGGUNA ALIH FUNGSI BANGUNAN(Studi Kasus : Perubahan Fungsi Ruang Kelas Menjadi RuangPerpustakaan Pada Lantai II Gedung G Universitas Semarang)," Forum Teknik Sipil No. XVIII/1-Januari 2008

Khalifa A, Gold W, Nanni A, and Abel-Aziz M., "Contribution of externally bonded FRP to shear capacity of RC Flexural Members," journal of composite for contruction, vol.2 no.4, 1998, pp 195-203

PT. Sika Indonesia., "Sikadur®-330 2-part epoxy impregnation resin." Technical Data Sheet Edition 2, 2005, Identification, no.020401040010 000004, Version no. 0010, Sikadur® 330, Jl. Raya Cibinong- Bekasi km. 20, Limusnunggal- Cileungsi, BOGOR 16820 - Indonesia, Tel. +62 21 8230025, Fax +62 218230025 , Website : www.sika.co. id, e-mail: sikacare@id.sika.com.

PT. Sika Indonesia., "SikaWrap ${ }^{\circledR}-231$ CWoven carbon fiber fabric for structural strengthening," Technical Data Sheet, Edition 1, 2008, Identification no.02 0401020010
000010, Version no. 0010, SikaWrap ${ }^{\circledR} \quad-231 \quad$ C, Jl. Raya Cibinong- Bekasi km. 20, Limusnunggal- Cileungsi, BOGOR 16820 - Indonesia, Tel. +62 21 8230025, Fax +62 218230025 , Website : www.sika.co. id, e-mail: sikacare@id.sika.com.

PT. Sika Indonesia., "SikaWrap $®-230$ C/45Woven carbon fiber fabric for structural strengthening," Technical Data Sheet, Edition 4, 2008, Identification no. 020401020010 000025, Version no. 0010, SikaWrap ${ }^{\circledR} \quad-230 \quad \mathrm{C} / 45, \quad J l . \quad$ Raya Cibinong- Bekasi km. 20, Limusnunggal- Cileungsi, BOGOR 16820 - Indonesia, Tel. +62 21 8230025, Fax +62 21 8230025, Website : www.sika.co. id, e-mail: sikacare@id.sika.com.

R. Brown, A. Shukla and K.R. Natarajan., "FIBER REINFORCEMENT OF CONCRETE STRUCTURES." University of Rhode Island, URITC PROJECT NO. 536101, September 2002

Triantafillou T.C, 1998., "Shear strengthening of reinforced concrete beams using exopy-bonded FRP composite," ACI journal structural journal, vol.95, no.2, 1998, pp 107-115

Uji, K., "Improving shear capacity of existing reinforced concrete members by applying carbon fiber sheet," transactions of the japan concrete institute, vol.14, 1992, pp.253-266 